\title{
A problemática dos indivíduos, suas lutas e conflitos no turbilhão da informação
}

\section{Mirian de Albuquerque Aquino}

\begin{abstract}
Doutora em Educação; Professora e Pesquisadora do Programa de Pós-graduação em Educação e do Departamento de Biblioteconomia e Documentação da Universidade da Paraíba.
\end{abstract}

O texto aborda a expressão sociedade da informação e seus diferentes significados no contexto das tecnologias da informação e comunicação, focalizando as repercussões dessas tecnologias no cotidiano dos indivíduos. Argumenta que, nessa nova ordem informacional, as tecnologias não atingiram sequer um terço da população menos favorecida economicamente, fato este que reforça cada vez mais o paradigma da exclusão e o processo de degradação das relações sociais, provocando uma disparidade na sociedade da informação e conhecimento.

Palavras-Chave: sociedade da informação; tecnologias da informação e comunicação; Profissionais que pensamconhecem-agem sobre a informação; Formação.

\section{The individuals problem, struggles and conflict facing the emergence of information}

This text approaches the expression information society and its diverse meanings in the fields of the information and communication technology, focusing on the effects of such technologies in daily life. It argues that in this new informational paradigm the technology does not even reach one third of the poor population, reinforcing the paradigm of segregation and the process of degradation of the social relationship, provoking a gap in the knowledge and information society. 
Keywords: Information Society; Information and communication technology; Think-know-act professionals; Formation.

\section{No turbilhão, a força do termo}

As sociedades do mundo inteiro estão em plena corrida para entrarem em uma nova fase da história da humanidade em que a informação passou a desempenhar um papel fundamental no cotidiano dos indivíduos. Trata-se de uma sociedade que se articula com 0 conhecimento, cujos sintomas enredam-se na complexidade do tempo e espaço que se emaranham nos fios de contradições, nas novas formas de expressões e novos conceitos intermináveis, construindo sistemas sociais e econômicos altamente complexos e demandantes de um intensivo trabalho de informação. São novas dinâmicas socioeconômicas e informacionais propiciando uma compreensão de que os indivíduos estão encarando um estágio de desenvolvimento nunca antes visto na história da humanidade.

Essas mutações, quando atribuídas às reflexões do sociólogo espanhol Manuel Castells, sinalizam para "um novo modo de desenvolvimento, cuja fonte de produtividade está centrada na geração de conhecimentos, armazenamento, processamento, uso da informação e comunicação de signos e símbolos" (CASTELLS, 1999, p. 35). Nesse complexo turbilhão de informação e conhecimento, diferentes nomes têm sido utilizados por autores de variadas tendências para designarem a nova sociedade e suas mutações socioculturais: sociedade pós-industrial (BELL, 1973); terceira onda (TOFFLER, 2000); sociedade do conhecimento (MATOS, 1982); sociedade da informação (MASUDA, 1982), sociedade informática (SCHAFF, 1990); sociedade pós-capitalista (DRUCKER, 1980); sociedade digital (NEGROPONTE, 1995); sociedade informacional (CASTELLS, 1996; 1999) sociedade aprendente (ASSMANN, 2000); sociedade da aprendizagem (BURNHAM,2000); sociedade em rede, sociedade informacional, sociedade dos fluxos (CASTELLS, 1996; 1999); sociedade de controle (DELEUZE, 2000).

Alguns estudos e pesquisas apontam, entretanto, uma dificuldade terminológica que se interpõe à compreensão da expressão sociedade da informação no contexto das TIC, forçando autores como Castells $(1996 ; 1999)$ a denominá-la de sociedade informacional, por vislumbrar uma sociedade que se caracteriza por fluxos e redes de informação de vários tipos. Essa expressão que o autor utiliza indica os...

... atributos sociais de geração e processamento da informação que vão do impacto das tecnologias da informação à informação em si mesma, [...] a tecnologia não é somente a ciência e as máquinas: é também tecnologia social e competitiva (CASTELLS, 1996, p.4). 
Também temos análises que vêem a sociedade da informação aprisionada a um emaranhado de fios complexos, vinculados a uma série de eventos importantes, como tentativas de previsão social, políticas governamentais, especulação futurista e análise sócio-empírica (LYONS, 1992; CASTELLS, 1996). No Brasil, há autores que assumem pontos de vista que, ora se voltam para o espírito da globalização, ora para o espírito da mundialização, fazendo alusão a metáforas e símbolos e produzindo significados que caracterizam a atual sociedade (ORTIZ, 1994; DREIFUSS, 1996; IANNI, 1997).

Os trabalhos de Bell (1973) articulam a sociedade da informação às tecnologias e servem para uma compreensão mais aprofundada sobre a gênese da sociedade da informação e de seus desdobramentos, apontando a estreita relação com a informação e o conhecimento, nesses últimos vinte anos. Essa visão revela que um dos fios dessa sociedade está conectado à idéia de pós-industrialismo, porquanto, admite Bell, se a sociedade agrária foi substituída pela sociedade industrial devido ao deslocamento da ênfase econômica da terra para a indústria é provável que a sociedade pós-industrial tenha nascido como conseqüência da crescente relevância econômica do setor da prestação de serviços.

O autor vai sustentar que o papel cada vez mais importante desempenhado pela ciência no processo produtivo, assim como a ascensão de grupos profissionais, científicos e técnicos e a tecnologia da informação contribuíram para o aparecimento de um novo princípio axial organizador do núcleo da economia e da sociedade, que se assume como alicerce lógico da centralidade do conhecimento teórico. Em diversos momentos de suas teses, Bell (1973) coloca a sociedade da informação no contexto do pós-industrialismo, cuja dinâmica previa um novo quadro de referência social com base nas telecomunicações, produzindo uma vasta organização do modo como os indivíduos se comunicavam entre si e envolvendo as formas de transmissão de dados, a redução ou eliminação, o papel nas trocas e transações, os modos de emissão de notícias, entretenimentos e conhecimento.

Lyons (1992) recusa os argumentos de Bell, por este autor ter subestimado o fato de que tecnologias são um prolongamento dos poderes militares, empresariais e governamentais, em sua função de monitoramento e supervisão das atividades dos sujeitos, gerando novas formas de conflitos e lutas. Nesse sentido, é válido lembrar as palavras de Deleuze (2000, p.216):

Estamos entrando em uma sociedade de controle que funciona não mais para confinamento, disciplina, mas por controle contínuo e comunicação instantânea [...]. O que está sendo implantado, às cegas, são novos tipos de sanções, de educação, de tratamento e vigilância.

Retomamos Lyons (1992) que considera a sociedade da informação idealizada por Bell como uma utopia em que os indivíduos estão vivendo novas divisões sociais e realinhamento de poderes, enquanto os grupos sociais disputam a apropriação e a distribuição das tecnologias na 
sociedade. Em sua crítica, Lyons (1992, p. 5) comenta que "o uso das tecnologias no governo, na educação, nas mídias, no campo doméstico e no trabalho, corroboram para que cada vez mais relacionamentos sociais sejam mediados pelas máquinas"

Para atualizar tal ponto de vista, ele busca Alain Touraine que enfatiza: os conflitos e os movimentos sociais de diferentes grupos apontam alterações de poder mais amplas e determinadas pelo poder que as TIC exercem sobre diversos setores da vida humana.

Ele incorpora direções múltiplas que assumem as análises que tomam como foco o impacto social das TIC, dentre as quais detemos em duas visões. A primeira refere-se à previsão de uma transformação social completa que culmina na sociedade da informação e conhecimento. Temos, de um lado, os futurólogos que naturalizam um discurso em que a riqueza, o poder, a paz e a democracia reinarão na sociedade da informação. Além disso, os problemas ambientais e ecológicos, as formas participativas de governo e a democracia computadorizada são temas que fazem parte do mundo futurista da sociedade da informação. Do outro lado, estão os planejadores que defendem o modelo japonês de uma sociedade cuja dinâmica seria capaz de favorecer globalmente a criatividade intelectual humana, em lugar de proporcionar um maior poder de aquisição de bens de consumo (MASUDA, 1982). Essas explicações dos futuristas e dos planejadores não convencem Lyons (1992), porque se encaminham no mesmo sentido de apoiarem e reforçarem a concepção de que a transformação da sociedade constitui um movimento desejável por todos os indivíduos. O autor diz que os produtores das tecnologias e os facilitadores da inserção delas no cotidiano dos indivíduos ignoram que os seres humanos são ativos, reflexivos e capazes de resistirem aos arranjos sociais e tecnológicos.

A visão unidirecional dos impactos sociais das TIC é um ponto crítico para Lyons (1992), porque essa maneira de pensar as tecnologias sugere que estão situadas fora da sociedade. As TIC são produtos sociais da mesma forma que a moldagem da sociedade é, em si mesma, um produto tecnológico. Para o autor, a existência de uma interação constante entre sociedade e a tecnologia está ligada a dois importantes fatores: 1) as TIC têm suas origens sociais na pesquisa militar $e ; b)$ exerceram influência decisiva no seu desenvolvimento, mas nem sempre são aceitas e assimiladas de forma passiva pelos cidadãos. Diante dessa situação, é necessário conjugar o desenvolvimento e a ética para indagar sobre o que é possível levar em conta como tecnologia a serviço de todos os indivíduos. Assumir esse caráter conflitivo que envolve indivíduos e tecnologias implicaria renunciar a toda ilusão de transparência dos discursos que vê a tecnologia em sua capacidade de moldar a sociedade, agindo de forma autônoma.

Em suas análises, Castells (1996, p.15) retoma a relação tecnologia, sociedade e poder para mostrar que...

.... caráter estratégico das tecnologias na produtividade da economia e na eficácia das instituições sociais muda as fontes 
de poder na sociedade e entre as sociedades [e] o controle da ciência e da técnica das tecnologias da informação chega a ser uma fonte de poder em si mesma.

No entanto, o comentário de Lyons (1992) expressa certo desencantamento com o determinismo tecnológico, pelo fato de considerar que as TIC acarretam várias conseqüências sociais ainda não previstas e, em certas circunstâncias específicas, possuindo ramificações não intencionais, a exemplo da vigilância estatal, da gestão intermediária e das redes globais de comunicações. Sua preocupação é clara: aqueles que estão enfeitiçados pelas tecnologias negligenciam fatores e processos que as envolvem, como as desigualdades significativas inerentes ao mercado de trabalho. O problema está na ausência de realismo, pois existem processos contraditórios não apenas com a perda das qualificações na atualidade. Ele comenta que suas críticas não devem ser entendidas como uma forma de resistência à busca de uma sociedade mais justa com base nas TIC, mas chama atenção para uma importante questão: os sistemas computadorizados afetam "a própria essência da organização industrial ao mesmo tempo em que contribuem para alterar certos aspectos do capitalismo, o que nos obriga a reavaliar todos os velhos conceitos e teorias" (LYONS, 1992, p. 11).

\section{A recomposição da engrenagem, desvios e processos de exclusão}

O aprofundamento das análises de Dreifuss (1996) conduz-nos para o final dos anos 1970, quando as transformações impulsionadas por países do hemisfério Norte começam a modificar as feições da sociedade mundial, promovendo uma ressignificação e uma redistribuição das riquezas das nações, pondo no limbo as referências doutrinárias, as dialéticas e as diversas certezas teóricas existenciais e os estados de bemestar que emergem na contemporaneidade, vislumbrando a incerta e desconcertante futuridade. $\mathrm{O}$ autor diz que a maioria dos países do Sul experimentou a noção de perda de oportunidade para acompanhar os novos movimentos, compreendê-los e explicá-los. As perdas são reforçadas pela incompreensão quanto ao sentido, aos objetivos e às conseqüências das implicações das descobertas e inovações tecnológicas e de seus desdobramentos societários e vivenciais e da ação econômica, política e cultural dos estados nacionais e das estruturas de poder dos países do Norte.

A maior preocupação, como sugere Dreifuss (1996), é de que não se trata de um simples reposicionamento e, sim, de uma profunda recomposição do sistema produtivo global e da conflitante constelação de poder mundial, anunciando o fim da cultura industrial, ameaçada pelo processo de instalação da comunicação digital. Essa mutação aponta um quadro de sombrias perspectivas e trágicas incertezas do presente para um número significativo de nações, povos e grupos sociais diversos, mergulhados num futuro comprometido por um crescimento mínimo, 
reduzindo-se a uma estagnação ou regressão completa. Nesse período de desindustrialização, remessas e transferências exorbitantes de capitais e evasão de recursos humanos, observou-se uma crescente evasão de trabalhadores qualificados. Além disso, as estatísticas mostram o crescimento das doenças evitáveis, determinando conseqüências sociais drásticas. São mutações modeladas por acelerados processos em curso de diferenciação, diversificação e recomposição econômica e políticoestratégica - que espelham a transformação das bases científicotecnológicas e culturais das sociedades avançadas nas modalidades de produção e nas formações societárias que apontam para movimentos de mutação civilizatória, configurados em menos de 20 anos.

Os movimentos são acelerados e sustentados por microprocessadores com transistores do tamanho de um cartão de crédito; por computadores baseados na opto eletrônica e sensíveis ao comando oral e por software inteligente, com capacidade de administrar redes de computadores hipercomplexas e multiplicidade das funções que reorganizam o cotidiano dos sujeitos, impondo-lhes mudanças em sua configuração e traçado; por mecanismos de transmissão de informação, cuja velocidade circula numa densa mega rede global de fibras óticas, conexões por satélites, elos sem fio e circuitos de imagem digital. Essas mutações envolvem a criação de espaços societários informados, sóciomercados informatizados e a configuração de novas composições sociais em torno de paradigmas produtivos e necessidades de consumo emergentes, referenciadas por inovadores modos de vida. Estes são indispensáveis para a própria potencialização da infra-estrutura de pesquisa e desenvolvimento e as avançadas estruturas (DREIFUSS, 1996) de informação e conhecimento que visam beneficiar apenas poucos indivíduos.

\section{Emergência, movimentos, difusão e processos de exclusão}

Segundo Lyons (1992), Masuda já antecipava que a sociedade da informação seria completamente diferente da sociedade industrial, porque a produção de valores informacionais se constituiria na força matriz da formação e do desenvolvimento. O autor já projetava uma sociedade construída dentro de um contexto inteiramente novo, partindo de análise completa da tecnologia de telecomunicações e informática, porquanto a revolução dessa última determinaria a sua natureza fundamental.

A complexidade dos novos tempos imposta pela sociedade da informação serve para introduzir, de modo mais específico, o processo de invasão e onipresença das TIC nas sociedades pós-industriais, os mecanismos da mudança técnica e as formas como essas tecnologias vêm mudando o mundo, resultando em demandas sociais e institucionais para realização de determinadas tarefas, sendo também responsáveis por uma série de transformações das necessidades básicas de nossa vida. 
A atual sociedade da informação surge com uma diferença básica: "o novo conhecimento é aplicado principalmente aos processos de geração e ao processamento do conhecimento e da informação" (CASTELLS, 1996, p. 11). Essa revolução tecnológica, em processo, como todas as revoluções anteriores, produz efeitos intersticiais em quase todas as esferas da atividade humana. A ênfase na geração, processamento e aplicação da informação e do conhecimento desenvolve um estado de espírito, permanentemente, estimulado por uma gama sempre em expansão de hardwares, softwares, aparatos e aplicações tecnológicas e promessas de salvação econômica, estimulação e aperfeiçoamento cultural, por meio da tecnologia (KENWAY, 1998).

Tal modo de desenvolvimento modifica, essencialmente, o conceito de tecnologias e se expressa como: "uso de conhecimentos científicos para especificar as vias de se fazerem as coisas de uma maneira reproduzível" (CASTELLS, 1999, p. 49-51). Este autor discute as repercussões das TIC nos avanços das fontes de energia, das aplicações na medicina, das técnicas de produção (nanotecnologia) e da tecnologia de transportes, entre outros, incluindo a microeletrônica, telecomunicações/radiodifusão, opto eletrônica, engenharia genética, suas aplicações e materiais.

Em artigo intitulado "História contemporânea e desenvolvimentos tecnocientíficos", Caron (2002) propõe os conceitos de interdependência e de sistema técnico como elementos necessários para uma melhor compreensão do caráter global do processo de mudança técnica, servindo também para explicitar as TIC como um processo coligado com duas experiências importantes na história das técnicas e das ciências. A primeira delas está ligada ao surgimento da eletricidade, entre 18801900, e a segunda está vinculada à emergência das tecnologias da informática, entre os anos 1960-1980, com o objetivo de atender não exclusivamente às necessidades militares, mas também responder a duas importantes dificuldades encontradas pelo sistema técnico: a) a da gestão e da regulação das redes e dos fluxos dos homens, das mercadorias e de informação no interior das redes; e b) a dificuldade da gestão da informação nas grandes organizações propriamente estatísticas, relacionada ao tratamento de arquivos e cadastros gigantescos, engendrados pela sociedade de massa (CARON, 2002).

O surgimento das TIC tem a ver com o desempenho satisfatório da IBM nas décadas de 1960 e 1970 que explicitará, em grande parte, a transferência da gestão mecanográfica saturada em que se tornara para enfrentar as exigências trazidas pela evolução do sistema técnico vigente e pelas necessidades de sociedade de massa que engendrara. 0 deslocamento provocado pelo disfuncionamento do sistema técnico gerou um diálogo entre o desenvolvimento do pensamento científico e a mudança técnica. É possível considerar que este diálogo apontava para a institucionalização da ciência no âmbito das universidades, seguida dos centros de pesquisa financiados pelo Estado ou empresa. Assim, por um lado, a ciência pura fortaleceu-se com o objetivo de desenvolver o conhecimento do universo, respondendo às pretensões de universalismo, 
desinteresse e ceticismo organizado e, por outro, a ciência aplicada consolidou-se com sua lógica de obtenção de resultados que podem ser comercializados ou servir para tornar eficiente a empresa para a qual trabalha (CARON, 2000).

O avanço dessas ciências torna-se intensivo pelo reforço dado pela institucionalização da pesquisa e massificação dos meios com os quais se defrontava, chegando a se vincular aos grandes programas de instituições de pesquisa dotados de meios técnicos, a exemplo do Projeto de Manhattan, reconhecidos como geradores de uma megaciência, originários dos Estados Unidos e da Alemanha, nos anos 1880-1914. Essa dinâmica intensificará uma competitividade para a instauração do binômio pesquisa-desenvolvimento, projetando o imperialismo dos Estados e o sucesso das empresas, dissipando-se a dúvida de que a ciência pura não seria útil à evolução dos saberes técnicos.

A partir dos anos 1970, enfatiza Caron (2002), o sistema técnico integrará o conhecimento científico em seus processos de concepção e de produção de produtos, sendo que os procedimentos de investigação científica passam a fornecer à pesquisa industrial os meios de conhecimento dos processos em lugar das experimentações. Nota-se que a pesquisa fundamental mantém um diálogo com os setores de alta tecnologia (a eletrônica e a biotecnologia) e com os setores da média tecnologia (automóvel), intensificando as relações com as universidades e os centros de pesquisa, montando sistemas de produção, cada vez mais, diretamente inspirados em concepções científicas resultantes dos avanços recentes da ciência. Nesse momento, nasce dos pesquisadores e dos engenheiros a ambição de construir uma sociedade nova, isenta de suas aspirações e desejos, porquanto se buscava a melhoria dos níveis de vida e das condições de trabalho, uma vez que a técnica era percebida como instrumento de liberação do homem. Essas necessidades humanas marcam as tecnologias da segunda revolução industrial dos anos 18801900 , com interesse na busca de procedimentos que permitissem colocar inicialmente novos produtos à disposição do grupo dominante, estendendo mais as possibilidades para os novos consumidores do século XIX. Esses processos de inovação e de difusão das tecnologias deveriam responder às demandas dessa sociedade de consumo, produzindo novos sistemas de valores e de comportamentos que se acomodarão às exigências adequadas ao século $\mathrm{XX}$.

Para Caron (2002), a difusão das TIC com o perfil que temos hoje é uma extensão do movimento que se estendeu desde a revolução pósindustrial. Certamente, não pode ser analisada como puro produto de um aproveitamento da pesquisa científica, mas resulta de uma necessidade de lazeres culturais e de comunicação intensamente percebida pelos engenheiros responsáveis pelas técnicas do rádio, da televisão e da Internet. A emergência e difusão das TIC, que se dá com o consenso e a comunicação de massa, não são mais interpretadas como o cumprimento das aspirações de uma sociedade em movimento, mas conseqüência de uma estratégia de oferta agressiva, por parte dos atores da mudança técnica: empresas, Estados e engenheiros. Essa dinâmica do sistema 
técnico repousa também sobre "uma excitação dos desejos, constantemente exacerbados pela renovação permanente dos produtos e dos serviços oferecidos ao apetite ilimitado do consumidor" (CARON, 2002, p. 417). Em síntese, diz o autor, essa avidez pelo desenvolvimento das TIC resulta da formação e do impulso de quatro aspectos: a tecnologização do cotidiano, o desenvolvimento das redes, a automatização dos modos de produção e a tecnologia do armamento.

Pautada numa lógica de mercado inseparável das formas políticas e econômicas, as TIC são consubstanciadas como um determinado projeto político (ASSMANN, 2000) que, por um lado, apresenta imensas potencialidades positivas, mas, por outro, carrega igualmente uma série de riscos, fertilizando uma imagem do mundo por demais complexa e desigual. Nesse sentido, a posição de Castells (1999, p. 51) é a de acentuar a presença das TIC na sociedade e seu papel na geração e processamento da informação, com aplicação na produção de conhecimento, as quais estão ligadas a processos a serem desenvolvidos, de modo que a mente humana é uma força direta na produção, não apenas um elemento decisivo no sistema produtivo.

O novo paradigma tecnológico reúne inovações técnicas, organizacionais, administrativas, produtos e sistemas, incluindo processos sociais que representam a base material da sociedade, caracterizada pela informação como matéria-prima e parte integral de toda a atividade humana em sua penetrabilidade, lógica das redes e flexibilidade $A$ origem dessa transformação liga-se a três fenômenos inter-relacionados: 1) a convergência da base tecnológica altamente integrada ao sistema de informação, capaz de representar e processar qualquer tipo de informação de uma única forma, a digital (?); 2) a dinâmica da indústria, responsável pelo aparente baixo custo dos computadores, com vistas à popularização; e 3) o crescimento da Internet, como decorrência dos dois primeiros fenômenos (TAKAHASHI, 2000).

Embora o autor considere que esse paradigma constitui um dos fundamentos da nova sociedade, também sugere que a crítica do modelo deve ser uma atitude permanente, pois se, por um lado, representa uma transformação qualitativa da experiência humana, tendo a informação como o principal ingrediente da organização social, por outro, não implica dizer que todas as pessoas estão participando dos benefícios sociais. Cada vez mais, essa nova ordem parece uma desordem social. É necessário manter acesa a idéia de que essa modernização propiciada pelas TIC ainda não atingiu um terço da população brasileira, menos favorecida economicamente, reforçando o paradigma da exclusão e o processo de degradação das relações sociais, os quais provocam uma disparidade na sociedade da informação e conhecimento: os enriquecidos, por serem detentores de mais informação, e os destituídos da condição humana, por terem menos informação.

Reconhecendo essa mutação sociocultural, em seu livro "A condição pós-moderna", Lyotard (1989) mostra uma apreensão quando assinala que o saber (informação) pós-moderno não é apenas o instrumento de poderes. O autor refina a nossa sensibilidade para enxergarmos as 
diferenças e a necessidade de fortalecermos a capacidade de suportar o incomensurável. Em suas reflexões filosóficas, vê a informação muito mais mercantilizada do que mesmo uma prática social, pois, ao invés de serem difundidas em seu caráter formador, as informações tornam-se objetos de transação econômica. Diante dessa situação, aquele autor postula que existem duas formas de saber (informação): uma positivista, que encontra a sua aplicação nas técnicas relativas aos homens e aos materiais, tornando-se uma força produtiva necessária ao sistema; $e$, a outra, crítica, reflexiva ou hermenêutica que interroga, direta ou indiretamente, sobre os valores ou as finalidades, obstaculizando qualquer recuperação.

Por outro ângulo, temos as análises sociológicas que consideram a conjugação da informática com as telecomunicações como o início de um novo modo de desenvolvimento e parece sugerir que a chave da riqueza das nações e modos diferentes de vida está na aprendizagem dos processos de manipulação, de disseminação, de armazenamento e de obtenção da informação. Assim sendo, qualquer orientação que se dissocie dessa nova ordem sociocultural está sujeita a sanções, com conseqüências fatais para os países menos desenvolvidos.

Tal advertência traduz a idéia de que é impossível alcançar o sucesso em todos os setores da atividade humana, sem recorrermos às TIC. Diante desse quadro irreversível, os países com menos recursos nutrem-se do receio de serem engolidos por esse novo império transnacional ou de se tornarem tecnologicamente dependentes dos EUA ou do Japão. Por essa razão, o objetivo que persegue a criação de uma sociedade da informação é o mesmo para os países capitalistas da América do Norte e para os estados comunistas, como a China e o Vietnã (FALKNER-BROWN, 1999).

O Brasil instaurou o Programa da Sociedade da Informação, com a perspectiva de que seus benefícios efetivamente alcancem a todos os brasileiros, divisando a importância do conhecimento como "um dos principais fatores de superação da desigualdade, de agregação de valor, criação de emprego qualificado e de propagação de bem-estar" (SARDENBERG, 2000, p. 5), firmando assim a posição que deverá ocupar no cenário internacional, enquanto milhares de indivíduos sucumbem no submundo das favelas, do crime organizado e da corrupção dos gestores da política nacional.

A resistência à idéia de construção de uma sociedade da informação e, doravante, sociedade da informação e conhecimento continua convencendo alguns indivíduos de que não passa de algo irreal, enquanto outros ainda a enfrentam com suspeita e hostilidade (CASTELLS, 1999). Paralelas a essas questões, as TIC vão se transformando em algo cada vez mais importante, tanto em nível local quanto em nível global, aparecendo por todos os lados grupos e movimentos que lutam pela reorientação desse novo modo de desenvolvimento ou por uma maior participação nos bens culturais.

Sem dúvida, as possibilidades indefinidas que as TIC, em seus rios de informação, colocam para os indivíduos, requerem uma mente capaz 
de pensar e transformar a informação em conhecimento pertinente, situando qualquer tipo de informação em seu contexto (MORIN, 2000). Exige a mobilização da estrutura cognitiva para organizar o conhecimento. Esse princípio de organização do conhecimento pressupõe a relevância do sentido que o profissional que pensa-conhece-age sobre a informação (AQUINO, 2004) atribui as coisas, a capacidade de perceber os objetos de seu trabalho, as pessoas que o procuram, os acontecimentos e as relações que se estabelecem com todos os objetos que o envolvem. Nesse esforço de compreender sua própria atividade, o profissional que pensa-conheceage sobre a informação precisa compreender que, essa prática de recolocar a informação em seu contexto, é válida para sua atividade técnica e igualmente válida para sua atividade acadêmica e reflexiva.

As TIC são produtos de uma nova sociedade e de uma cultura e Lévy (2000) a dissocia da metáfora impacto por ser inadequada para discutir as técnicas de imaginação, concepção, fabricação, reinterpretação e utilização pelos homens, em sua estreita ligação com o ambiente material, os signos, as imagens, a linguagem, por meio dos quais atribui sentido à vida e ao mundo. Essa consideração levyniana postula que as verdadeiras relações não são criadas entre a tecnologia e a cultura, mas por um grande número de atores humanos que inventam, produzem, utilizam e interpretam de diferentes formas as técnicas. O autor afirma que, por um lado, um certo número de idéias, projetos sociais, utopias, interesses econômicos, estratégias de poder estão subjacentes às técnicas, manifestando uma gama de jogos dos homens em sociedade; mas, por outro, elas também respondem aos propósitos de desenvolvedores e usuários que procuram aumentar a autonomia dos indivíduos e multiplicar suas faculdades cognitivas.

\section{Processos socioculturais afetando produtos, serviços e indivíduos}

Conhecida como propulsora do desenvolvimento de microcomputadores resultantes de processos técnicos, a década de 1980 possibilitou a centenas de instituições, incluindo as bibliotecas e unidades de informação, a aquisição de sistemas próprios de computação. Já em meados dos anos 1990, os computadores pessoais (PC) tornaram-se lugares comuns nas bibliotecas e unidades de informação mundialmente. Em decorrência, os avanços paralelos na velocidade de processamento, facilidades de armazenamento, multimídia e telecomunicações possibilitaram o acesso aos mesmos recursos informacionais em todo 0 mundo.

Nesse contexto sociocultural, a visão tradicional de biblioteca como um estoque de informações (acervo), mantido localmente, acabou sendo substituída, à medida que a nova biblioteca (digital, virtual ou eletrônica) transformou-se em portão de entrada para os recursos mundiais de informação, sendo possível conectar terminais ou estações de trabalho em bibliotecas remotas, filiais ao sistema principal, ou interligar vários PCs em atividade de compartilhamento ao acionador de CD-ROM ou a uma 
impressora, trazendo significativas implicações para usuários de bibliotecas, provedores de informação, bibliotecários e cientistas da informação (TODD, 1999).

Na Europa Ocidental, segundo Todd (1999), as mutações políticas ocorridas na década de 1990 contribuíram para a abertura do mercado de sistemas bibliotecários em vários países (Croácia, República Tcheca, Hungria, Polônia, Eslováquia e Eslovênia). Em 1994, a automatização de bibliotecas criou o Programa de Bibliotecas Regionais do Instituto de Sociedade Aberta de Hungria e Budapeste, com o objetivo de apoiar, promover e avançar as ciências da informação na Europa Central e Oriental e na Comunidade de Nações Independentes, com sugestão de metas de longo prazo para o acesso automatizado à informação de bibliotecas.

O crescimento de redes exerceu pressão sobre os sistemas de gestão de biblioteca para se tornarem, cada vez mais, dependentes da adesão aos padrões internacionais. Essa exigência injeta uma crítica na performance das TIC e sua repercussão nas bibliotecas, arquivos e sistemas de informação, por se observar uma preocupação em dispor de equipamentos e programas sofisticados, mas pouco se investir no sentido de rever práticas profissionais e assegurar que sejam observados aspectos ergonômicos, os quais podem ser entendidos como um conjunto de estudos que visam à organização metódica do trabalho em função do fim proposto e das relações entre o homem e os computadores, em projetos de estações de trabalho compatíveis com as condições de produção da formação da qualificação exigidas pela sociedade da informação e conhecimento (TODD, 1999).

O desenvolvimento das TIC coloca uma tensão para o serviço público de difusão da informação e para as bibliotecas públicas. Sem desconsiderar as desvantagens trazidas pela sociedade da informação e conhecimento e das TIC, o novo modo de desenvolvimento e suas inovações são fundamentais ao progresso de qualquer sociedade e às atividades profissionais (CASTELLS, 1999). O computador tem afetado o trabalho de informação nas organizações, empresas, universidades, arquivos, museus e bibliotecas. No entanto, as resistências não são mais do que a manifestação diante de uma dinâmica contraditória muito profunda, já que as bibliotecas públicas ainda padecem da ausência de informações atualizadas, demonstrando que a "informação para cidadania", pelo menos para muitos, ainda é uma ilusão. Essa demanda de informação constitui um enorme desafio que o nosso País está enfrentando hoje para assegurar a posição da sociedade brasileira na dotação dos recursos, produtos e serviços de informação na rede (MIRANDA, 2000).

O setor da disseminação refere-se à criação e gestão de redes de comunicação e distribuição por meio das quais as informações são transmitidas, abrangendo operadores de telecomunicações e os indivíduos que utilizam os canais de difusão do conteúdo da informação (livrarias, bibliotecas, sociedades de difusão, fornecedores etc). O setor de tratamento da informação é constituído por fabricantes de hardwares 
(computadores, equipamentos de telecomunicações e eletrônica de consumo) e por produtores de softwares (UNIX, DOS e Windows).

O Livro Verde anuncia que arquivos e bibliotecas, museus e centros de informação cumprirão papel estratégico na mobilização de indivíduos e comunidades que ainda não estão conectadas e com acesso aos conteúdos da Internet (TAKAHASHI, 2000, p. 65). Quem tem acesso? Por quanto tempo? Interessante notar que o próprio Livro Branco reconhece a carência da sociedade brasileira em todos os setores dessa atual sociedade que requer uma maior expansão das TIC, com acesso e uso plenamente eficaz.

Uma outra contradição dessa sociedade sinaliza para os sistemas informacionais (bibliotecas, arquivos, museus, escolas etc.) que ainda estão obsoletos, devendo o Estado e o mercado incrementar a pesquisa e os acordos comerciais no campo das TIC para atender a um público maior. Trata-se de universalizar o acesso e o uso dos meios eletrônicos de informação para gerar um trabalho com a informação mais eficiente, em todos os níveis.

\section{As novas exigências para a formação requeridas pelo potencial das TIC}

A natureza da empregabilidade tem sido afetada, também, pelas mudanças estruturais que transformam os esquemas tradicionais de trabalho, com o surgimento de novas indústrias intensivas em informação. Exige-se, pois, que os empregados passem grande parte do tempo de sua jornada tratando a informação e trabalhando com a tecnologia da informação, para atender ao desenvolvimento da indústria da informação e seus conteúdos que afetam, direta ou indiretamente, as profissões e os profissionais da informação. Nesse sentido, Moore (1999) distingue três campos diferentes do setor da informação: conteúdos, disseminação da informação e tratamento da informação. O setor de conteúdo da informação é constituído por empresas, de caráter público e privado, que produzem e desenvolvem bens de propriedade intelectual. Esse conteúdo procede da criação de escritores, compositores, artistas e fotógrafos que recebem assessoramentos de diversos profissionais ligados à arte e à televisão.

As TIC repercutiram no trabalho e na economia, levando o mercado a formular novas exigências para o sistema educativo, surgindo a necessidade de atualizar o conteúdo de ensino, a fim de integrar novas descobertas científicas e tecnológicas e, também, utilizar novas ferramentas. Essa interferência produzida pelo desenvolvimento da informação expandiu o campo de atividade dos profissionais da informação, aumentando a quantidade de informação a ser acessada e tratada e criando uma demanda de serviços que exigem, cada vez mais, recursos e mentes qualificadas. Essas inovações colocam também a necessidade de se abrir novas áreas de formação que possibilitem requalificar os profissionais que pensam-conhecem-agem sobre a informação no ritmo das alterações referentes as suas especialidades. 
Junto a isso, a relação formação específica/formação geral surge como elemento imprescindível para que 0 indivíduo possa se inserir profissionalmente no mercado de trabalho.

As exigências de formação continuam a aumentar por causa da complexidade das sociedades, das dificuldades de inserção profissional de jovens não-qualificados e da corrida pela competitividade. Essa formação, entretanto, não pode mais ser pensada de acordo com os modelos tradicionais de ensino (LÉVY, 2000). Os novos desafios colocados pelas TIC alteraram o ambiente educacional, os currículos e os meios postos à disposição dos professores para o exercício da formação profissional, levando a escola (universidade) e seus professores a se conscientizarem acerca do papel da educação em relação aos novos meios de acesso à informação, disponíveis fora da instituição.

O Programa Sociedade da Informação no Brasil-Livro Verde faz uma observação à situação dos currículos nacionais, em sua perspectiva de formação, colocando a necessidade de uma revisão de seus fundamentos em todos os níveis e áreas. Chama a atenção, de modo particular, para as Ciências da Informação, vez que, no nível de graduação, em países como - Brasil, há currículos obsoletos, refletindo uma visão da área desatualizada em muitos aspectos essenciais, face à revolução das tecnologias de informação e comunicação (TAKAHASHI, 2000). Essa preocupação sintoniza-se com o pensamento levyniano, porque a demanda de formação não apenas reconhece um enorme crescimento quantitativo da informação, mas também tem sido afetada por uma profunda mutação qualitativa e a necessidade crescente de diversificação e de personalização dos estudos, pois "os indivíduos toleram cada vez menos seguir cursos uniformes ou rígidos que não correspondem a suas necessidades reais e à especificidade de seu trajeto de vida" (LÉVY, 2000, p.170) e suporta, menos ainda, tal conhecimento a população de indivíduos de diferentes culturas que estão chegando à escola ou universidade, tais como grupos culturais e étnicos.

Também não podemos esquecer que essa preocupação com o ensino de graduação em nível nacional, trazida pelo programa da Sociedade da Informação para o Brasil, é um fato novo, pois, durante anos, os discentes foram engessados em currículos que resultavam sempre de propostas geradas nos gabinetes dos burocratas do MEC, sob a orientação de ideologias dominantes, em detrimento da construção de um projeto coletivo, desrespeitando, assim, a inteligibilidade dos docentes e a autonomia das universidades e cursos.

Nessa nova ordem informacional em que se exige, fundamentalmente, uma educação multicultural, Lévy (1993) adverte que os novos dispositivos informacionais e comunicacionais são os maiores portadores das mutações socioculturais. Assim sendo, os desafios para a Ciência da Informação, em suas atividades de geração, organização, tratamento, acesso e uso da informação, provocam tensões na atividade profissional. Em primeiro lugar, essas tensões passam pelas novas linguagens impostas pelo desenvolvimento das TIC e sua redefinição das palavras informação, conhecimento, aprendizagem, ecoformação e 
competências, surgindo também em diferentes contextos as expressões sistemas com base no conhecimento, gestão do conhecimento, ecologia cognitiva e outras. Essas novas linguagens estão florescendo no contexto acadêmico e nas práticas informacionais, obrigando a profissionais que pensam-conhecem-agem sobre a informação a redefinirem conceitos e incorporarem também os novos paradigmas de informação.

Em sua análise, Assmann e Mo Song (2000) põe um acento maior na expansão das linguagens digitais que levou ao aparecimento explícito da sua incompletude, evidenciando-se a insuficiência operacional de uso das linguagens que se relacionam com o modo convencional de perceber a informação. Assim, as palavras aprendizagem, informação, conhecimento, formação e competência têm sido importantes não só para os economistas, que visualizam o mercado como uma máquina cognitiva, geradora do conhecimento e experiências de aprendizagem, como também para todos os profissionais que trabalham com a informação e o conhecimento.

Cabe-nos introduzir algumas perguntas: que papel os profissionais que pensam-conhecem-agem sobre a informação podem desempenhar nessa demanda de informação e conhecimento? O que as mutações lingüísticas significam para os profissionais que pensam-conhecem-agem sobre a informação ou, especificamente, os educadores em Ciência da Informação? A atual formação profissional responde aos interesses dessa sociedade da informação e conhecimento?

\section{Tensões de uma ciência frente os novos contextos de aprendizagem}

O computador e as novas mídias estão coincidindo com os avanços significativos em novas descobertas, provenientes das ciências cognitivas que tratam do cérebro/mente como um complexo dinâmico. Para Assmann (1998), as áreas de conhecimento devem buscar um princípio pedagógico que leve a atender essa complexa característica do ser humano no plano da construção de conhecimentos. O resultado será, fatalmente, o aprisionamento dos aprendentes em visões reducionistas acerca da realidade, com conseqüências drásticas para a criatividade cognitiva e a capacidade adaptativa dos sujeitos a essa realidade.

De modo geral, todas as áreas de conhecimento têm sido desafiadas a se aproximar dos movimentos interdisciplinares e transdisciplinares que acenam para novos contextos de aprendizagem. Nesse ponto, parece-nos que o desafio concreto para a formação de novas competências é o de atinar para a compreensão de que existe uma relação entre formas de aprendizagem e formas de vida, pois não é possível mais separar os processos mentais dos processos biológicos nem estes dos processos sociais.

O enfoque na junção desses processos pode levar os educadores a redefinir a formação como um conjunto de atividades propiciadoras e ativadoras de processos vitais, as quais seriam as formas vivenciais de experiência do conhecimento, porque, sem essa mobilização cognitiva, 
dificilmente haverá uma aprendizagem significativa e uma formação compatível com as exigências da sociedade da informação e do conhecimento. Por aprendizagem significativa, David Ausubel (apud MOREIRA, MASINI, 2001) entende "um processo pelo qual uma informação nova se relaciona com um aspecto relevante da estrutura de conhecimento do indivíduo". A apreensão da informação não ocorre por justaposição, mas como um processo de integração da estrutura cognitiva com a informação, pois sem essa conexão não há aprendizagem significativa.

Em síntese, diz Assmann (1998) com base nas novas teorias (biociências), há uma ligação entre processos vitais e processos de aprendizagem, resultando numa permanente expansão cognitiva. A questão da qualidade da aprendizagem exige novos enfoques de análise e interpretação da formação que permitam ver todos os aspectos da informação de maneira interligada, envolvendo não só os aspectos tradicionais da área que dão o caráter de ciência e asseguram sua especificidade, mas é necessário também dinamizar a gestão pedagógica e informacional, para aceitar as novidades tecnológicas na renovação das práticas de formação. Tais condições revelam que essa qualidade da aprendizagem passa pela atualização do currículo de graduação e das concepções de conhecimento e aprendizagem, enraizadas nas mentes dos docentes. Afirma Assmann que os cursos de graduação estão praticando um apartheid neuronal com relação ao potencial cognitivo dos aprendentes, excluindo as experiências de aprendizagem. Diante disso, indagamos: como articular formação de competências e novas experiências de aprendizagem?

Essa inquietação ressoa nas palavras de pesquisadores da Ciência da Informação, quando ressaltam que seu campo de conhecimento passou efetivamente por sistematizações e rearranjos, mas as mudanças paradigmáticas e, principalmente, as reformulações conceituais permaneceram despercebidas. Em seus escritos, incisivamente, Kobaiashi et al (2001, p. 8) assinalam que...

... quando a área de Ciência da Informação enfatizou em suas análises a tecnologia da informação, valorizando o novo e o recente, o processo foi extremamente rápido $[. .$.$] , impedindo$ a elaboração de sínteses, responsáveis por incorporações significativas ao campo de estudo.

Tal dificuldade tem sido interpretada não simplesmente pela transmutação de conceitos teóricos da Biblioteconomia para a Ciência da Informação ou de outras áreas afins, mas pelo receio de incorporar determinados conceitos, sem observar a especificidade da área $e$, de modo particular, na pós-graduação.

Prosseguindo a análise, as autoras sinalizam que "a alteração designativa [do campo] não correspondeu a um deslocamento qualitativo de reflexão, [pois] verifica-se que a maior parte de nossos cursos de pósgraduação é orientada para a análise de questões técnicas relacionadas com o processar, armazenar e recuperar informação" (KOBASHI et al, 
2001, p.2). Apoiando-se nas idéias de Aldo Barreto de Albuquerque, as autoras colocam uma outra preocupação: a atualização conceitual é fundamental no processo de geração do saber para a sociedade, mas se transforma em um mecanismo inibidor pela própria natureza do pensar acadêmico.

Dessa crítica, sobressai o nó górdio da Ciência da Informação e de suas práticas de formação profissional: a racionalidade predominantemente técnica ainda não foi transmutada para "racionalidade acadêmico-reflexiva", como uma condição fundamental à construção da identidade dessa área de conhecimento. Evidentemente, o caráter interdisciplinar que assombra a área em determinados momentos tende a afastá-la da reflexão disciplinar, atitude fundamental na constituição do seu objeto teórico (KOBAIASHI et al, 2003).

Para tentar resolver o problema que tensiona o campo da Ciência da Informação, parafraseando as idéias do conhecido pássaro-tecelão, Freire e Araújo (2001, p. 234) retomam as sínteses de Gernot Wersig para argumentar que "os problemas internos acontecem, por causa de complexidades e contradições nas situações sociais". Assim sendo, caberiam aos pesquisadores da área depreender esforços para reestruturar essa realidade caótica, procurando desvelar os atratores estranhos e suas contradições ou relações, para tentar reorganizá-los coerentemente com a utilização e redefinição dos conceitos disponíveis.

A autora reconhece nessa abordagem uma luta interna a ser enfrentada nesse campo de conhecimento, em duas fronteiras: por um lado, a percepção tradicional dos profissionais da informação que receberam uma formação voltada para as disciplinas clássicas e, por outro, a pouca familiaridade com as novas disciplinas científicas, porque suas atividades práticas envolviam, inicialmente, a construção de sistemas de informação orientados pelas disciplinas tradicionais. No entanto, consideramos que essas tensões não devem afastá-los da inter-relação com outras áreas do conhecimento, na busca incessante de conceitos novos e perspectivas inovadoras para a formação de competências.

Nessa relevância dada ao conhecimento, com enfoque para o aprendizado e a formação de competências, entendemos que as áreas de conhecimento devem adaptar-se às mudanças conceituais e atitudes práticas, para as quais ainda não dispomos de linguagens coerentes com o arcabouço conceitual desse campo de conhecimento.

\section{Considerações Finais}

Nessa imagem que a informação e o conhecimento estão em cena, tentamos compreender a passagem gradual da sociedade industrial para a sociedade pós-industrial, segundo a qual a característica básica está centrada na importância do conhecimento teórico e da tecnologia, engendrados por um novo grupo de profissionais especializados e altamente capacitados a promover o desenvolvimento da indústria e da sociedade, em que a informatização alcançaria diversas áreas da vida humana. Em conseqüência, o conhecimento tornou-se o recurso 
estratégico mais importante e nova força para a produtividade, valor e riqueza para os países considerados desenvolvidos.

A configuração das demandas socioculturais viabiliza a inserção do indivíduo numa sociedade que se potencializa com a velocidade e a penetrabilidade das tecnologias da informação, em sua capacidade de produzir conhecimento e fazer ressonância no cotidiano das pessoas, instituindo novas formas de comunicabilidade, agilidade, interatividade e sociabilidade nas relações. Essa compreensão expressa a necessidade de que devemos começar a buscar linguagens aproximativas, nas quais se possa notar a diferença dos enfoques teórico-metodológicos para a formação de competências, declinando da ilusão de contar com linguagens que expressem todos os aspectos do conteúdo formativo com clareza. Essa perspectiva de formação passa a imprimir uma nova forma de pensar, no intento de conseguir vivenciar a mudança.

É possível deduzirmos que a sociedade da informação e do conhecimento com suas TIC caracteriza um novo modo de desenvolvimento que atinge as ciências em suas várias dimensões, os indivíduos, o trabalho e campos de conhecimentos distintos. Nesse cenário complexo, a informação é a matéria-prima para gerar conhecimento, revelando o teor dos interesses econômicos. Assim sendo, terá acesso ao conhecimento quem tiver domínio do ciclo da informação que demanda os fundamentos teóricos do conhecimento formal para formar competências e desenvolver habilidades para interagir com os meios tecnológicos sofisticados.

O que nos parece claro é que, aparentando serem neutras em si mesmas, as TIC podem se constituir em fontes de desenvolvimento humano, ao invés de servir simplesmente como instrumentos de controle e manipulação. No entanto, compete aos indivíduos discernirem o que constitui fator de valorização, conhecimento, liberdade e solidariedade do que é alienação, manipulação, opressão ou injustiça. Esses princípios são importantes graças às inúmeras virtualidades que as TIC.

O que é possível reter desse panorama é que as TIC estão transformando inúmeros aspectos da vida cotidiana, acenando para uma mutação sem precedentes na evolução da espécie humana. Essa revolução tecnológica interfere nas tradicionais formas de trabalho, reorganizando a empregabilidade e acentuando a exclusão social como algo irreversível, rápido e profundo. Essa sociedade da informação e conhecimento só cumprirá seu papel no Brasil, portanto, se os projetos nacionais estiverem alicerçados em uma base democrática de universalização da informação, com vistas a instaurar uma política de (in)formação na perspectiva do acesso e uso das TIC plenamente capaz de garantir que todos os cidadãos possam ser educados e informados.

Entendemos que a disseminação da informação não supõe, simplesmente, a possibilidade de uma pluralidade de significados, mas a impossibilidade mesma de fixação de qualquer significado na formação de competências. Com essas palavras, supomos que a disseminação da informação para cidadania transporta uma multiplicidade invencível e geradora de múltiplos significados. Assim sendo, ao tentarmos 
compreender as particularidades e complexidades, ou mesmo, a essência da sociedade da informação e conhecimento, é necessário que discutamos a relação com o conhecimento e suas implicações para a formação de competências, devendo perceber os fios de sua ligação com o desenvolvimento das TIC.

Do nosso ponto de vista, as implicações para uma sociedade da informação e conhecimento no Brasil não estão simplesmente relacionadas à perda dos postos de trabalho e das qualificações, mas, sobretudo, ao fato de termos uma população pobre, com um alto percentual de afro descendentes ainda não incluído nesse processo mutacional. Diante desse quadro, é lícito interrogarmos: para quem a informação? Para quem o conhecimento? Como sabemos que a informação nesse paradigma tecnológico circula fortemente pela Internet, apontando para a concretização da informatização na sociedade, a distribuição dessa informação para gerar conhecimento ocorre, de modo assimétrico, reforçando cada vez mais as desigualdades sociais/raciais.

\section{Referências}

AQUINO, M. A. Ecologia informacional: da árvore da informação ao rizoma do conhecimento - desafios para formação humana na sociedade da aprendizagem. 2004. 212f. Tese (Concurso de Professor Titular em Ciências da Informação) - Centro de Ciências Sociais e Aplicadas, Universidade Federal da Paraíba, João Pessoa, 2004.

ASSMANN, H. e MO SUNG. J. Competência e sensibilidade solidária. São Paulo: Vozes, 2000.

ASSMANN, Hugo. Reencantar a educação. São Paulo: Vozes, 1998.

AUSUBEL, D. P. The Psychology of Meaningful Verbal Learning. New York: Grune \& Stratton, 1963 apud MOREIRA, M.A e MASINI, E.F.S. Aprendizagem significativa: a teoria de Ausubel. São Paulo: Centauro, 2001.

BELL, D. The coming of post industrial society: a venture in social forecasting. New York: Basic Books, 1973.

BURNHAM, F. T. Sociedade da informação, sociedade do conhecimento, sociedade da aprendizagem: implicações ético-políticas no limiar do século. In: LUBISCO, N. M. L; BRANDÃO, L. M. B. Informação \&Informática. Salvador: EDUFBA, 2000.

CARON, F. História contemporânea e desenvolvimentos técnicos científicos. In: MORIN, E. A religação dos saberes: o desafio do século XXI. Rio de Janeiro: Bertrand do Brasil, 2002.

CASTELLS, M. A sociedade em rede. São Paulo: Paz e Terra, 1999. v. 1.

CASTELLS, M. Fluxos, redes e identidades: uma teoria crítica da sociedade informacional. In: CASTELLS, M. et al. Novas perspectivas críticas em educação. Porto Alegre: Artes Médicas, 1996. (Educação, teoria e crítica). DELEUZE, G. Conversações. Rio de Janeiro: Editora 34, 2000.

DREIFUSS, R. A época das perplexidades: mundialização, globalização e planetarização - novos desafios. São Paulo: Vozes, 1996.

DRUCKER, P. F. Sociedade pós-capitalista. São Paulo: Pioneira, 1994. 
FAULKNER-BROWN, Harry. A sociedade da informação. In: A INFORMAÇÃO: tendências para o novo milênio, p. 99-108, Brasília: IBICT, 1999.

FREIRE, I. M.; ARAÙjO, V. M. R. H. Tecendo a rede de Wersig com os indícios de Ginzburg. Disponível em <http://www.dgz.org.br/ago01/Art 03.htm>. Acesso: 12 abri. 2001.

IANNI, Octavio. Teorias da globalização. 4 ed. Rio de Janeiro: Civilização Brasileira, 1997.

KENWAY, Jane. Educando cibercidadãos que sejam ligados e críticos. In: SILVA, Luiz Heron. A escola cidadã no contexto da globalização. Petrópolis: Vozes, 1998.

KOBAIASHI, N. Y. et al. A função da terminologia na construção do objeto da ciência da informação. 2001 Disponível em $<$ http//www.dgz.org.br/ab01/Art03.htm>. Acesso em: 22 mar. 2003.

LÈVY, P. As tecnologias da inteligência: o futuro do pensamento na era da informática. Rio de Janeiro: Editora 234, 1993. (Coleção TRANS).

LÉVY, P. Cibercultura. São Paulo: Editora 34, 2000.

LYONS, D. A sociedade da informação. Portugal: Celta, 1992.

LYOTARD, Jean-François. A condição pós-moderna. 5. Ed. Rio de Janeiro: José Olympio, 1998.

MASUDA, Yoneji. A sociedade da informação como sociedade pósindustrial. Rio de Janeiro: Editora Rio, 1982.

MATOS, J. M. A sociedade do conhecimento. Brasília: Ed.UNB, 1982.

MIRANDA, A. Sociedade da informação: globalização, identidade cultural e conteúdos. Ciência da Informação, Brasília, v. 29, n. 2, p. 78-88, maio/ago, 2000.

MOORE, M. A sociedade da informação. In: A INFORMAÇÃO: Tendências para o novo milênio, 1999. 211p.

MOREIRA, M.A e MASINI, E.F.S. Aprendizagem significativa: a teoria de Ausubel. São Paulo: Centauro, 2001.

MORIN, E. A. Da necessidade do complexo. In: MARTINS, F. M e SILVA, J. M. Para navegar no século XXI - tecnologias do imaginário e cibercultura. Porto Alegre: Sulina/Edipucrs, 2000.

NEGROPONTE, N. A vida digital. São Paulo: Companhia das Letras, 1995. ORTIZ, R. Mundialização e cultura. São Paulo: Brasiliense, 1994.

SANDEBERG, Ronaldo Mota. Apresentação. In: TAKAHASHI, Tadao (Org.). Sociedade da informação no Brasil: Livro Verde. Brasília: Ministério da Ciência e Tecnologia, 2000.

SCHAFF, A. A sociedade informática. São Paulo: Unesp, 1990.

TAKAHASHI, T. (Org.). Sociedade da Informação no Brasil: Livro Verde. Brasília: Ministério da Ciência e Tecnologia, 2000.

TODD, L. Avanços em computadores. In: A informação: tendências para o novo milênio. Brasília : IBICT, 1999. p. 11-25.

TOFFLER, Alvin. A terceira onda. Rio de Janeiro: Record, 2000. 